\title{
The study of the modification methylphenylsiloxane resin with dimethylene links metal compounds and boric acid
}

\author{
(C) Andrey M. Kontorov, ${ }^{+}{ }^{+}$and Boris B. Sergeev \\ State research center Joint stock company "State scientific-research Institute of chemistry and technology \\ Of Organoelement compounds”. EntuziastovAve., 38. Moscow,111123.Russia.E-mail: ankont2@yandex.ru
}

*Supervising author; ${ }^{+}$Corresponding author

Keywords: methylphenylsiloxane resin, alkoxysilane, thermal stability, elementlocalname fragments, NMR, IR-spectroscopy and TGA.

Abstract
In this paper we study the effect of modified metal compounds and boric acid $(\mathrm{E})$, where Element $=\mathrm{B}$, $\mathrm{Ti}, \mathrm{Zr}, \mathrm{Al}$ on the thermal stability of methylphenylsiloxane resins derived from alkoxysilanes.

Currently interested in the reaction for producing oligosilsesquioxanes based on acidolysis alkoxysilanes. In this regard, the author was tasked with obtaining new methylphenylsiloxane resins with different properties.

In this paper, we study the properties of new methylphenylsiloxane resins (MFSS), modified metal compounds and boric acid. New MFSS obtained by a new universal technology-acidolysis mixture of methyltriethoxysilane (MTEOS) and phenyltriethoxysilane (PHTEOS) with various radicals, which are environmentally friendly raw materials. The obtained MFSS were characterized by NMR spectroscopy on ${ }^{1} \mathrm{H}$ and ${ }^{29} \mathrm{Si}$ nuclei. The spectra were recorded at room temperature in deuteroacetone using a Bruker AM-360 Fourier spectrometer. ${ }^{29} \mathrm{Si}$ NMR spectra were measured using the pulse program "Inverse Gated Heteronuclear Decoupling".

Thermogravimetric analysis was performed on the device Derivatograph-H (firm Mom). TGA studies were carried out in the argon atmosphere and in air at a heating rate of $10^{\circ} \mathrm{C} / \mathrm{min}$.

The acidolysis reaction of methyltriethoxysilane and phenyltriethoxysilane is a convenient and versatile method for the synthesis of new heat-resistant methylphenylsiloxane resins. In the course of the study, it was found that the resins obtained on the basis of organoalkoxysilanes are characterized by higher thermal and thermo-oxidative stability. It is shown that the modification methylphenylsiloxane resin dimethylsiloxane links in the main chain elementlocalname fragments of $\equiv \mathrm{Si}-\mathrm{O}$-Element-O-Si $\equiv$, where element $=\mathrm{B}, \mathrm{Ti}, \mathrm{Zr}, \mathrm{Al}$ increases its resistance to the level methylphenylsiloxane resin without dimethylsiloxane links.

\section{References}

[1] L.M. Khananashvili, K.A. Andrianov. Technology of Organoelement Monomers and Polymers. Moscow: Khimiya. 1983. P.257.

[2] O.G. Ryzhova, A.M. Kontorov, A.N. Polivanov, M.U. Buzin. New thermostable oligomethylphenylsiloxanes on the basis of organoalkoxysilanes of different functionality. 5th European organosilicon days. Vienna. 2009. 183p.

[3] Process for preparing polyorganosiloxanes based on organoalkoxysilanes. Patent No 2428438 C2.2011. O.G. Ryzhova, P.A. Storozhenko, A.N. Polivanov, A.M. Kontorov, G.Ya. Zhigalin, O.L. Ershov, B.Ye. Kozhevnikov, A.V. Apal'kov, M.N. Perveev.

[4] Process for preparing heat resistant oligoorganosiloxane resins. Patent No 2464286 C1.2012. A.M. Kontorov, G.Ya. Zhigalin, O.L. Ershov.

[5] Process for preparing heat resistant polyorganosiloxanes based on. Patent application No 2013130624. O.G. Ryzhova, P.A. Storozhenko, A.N. Polivanov, A.M. Kontorov.

[6] A.M. Kontorov. New methylphenylsiloxane resin based on alkoxysilanes. Butlerov Communications. 2019. Vol.59. No.7. P.142-149. DOI: $10.37952 /$ ROI-jbc-01/19-59-7-142

[7] K.A. Andrianov. Methods of Organoelement chemistry of silicon. Moscow: Publishing House Nauka. 1968. (russian)

[8] S.N. Borisov, M.G. Voronkov, E.Ya. Lukevic. Organosilicon compounds. Derivatives neorganicheskoj, Monography. Leningrad: Chemistry. 1996. 544p. (russian) 
THE STUDY OF THE MODIFICATION METHYLPHENYLSILOXANE RESIN WITH DIMETHYLENE LINKS... _ $78-85$

[9] Method for producing polymetallosiloxanes with uniform distribution of metal and controlled ratio of silicon to metal in chain. Patent RU 2444540 C1. Mar 10, 2012. A.G. Ivanov, V.M. Kopylov, V.L. Ivanova, I.I. Khazanov, A.Yu. Shaulov.

[10] E.I. Kostyleva, T.I. Rybkina, I.M. Kostylev, V.M. Kopylov. Synthesis and properties of new metalcontaining organosilicon compounds. Izvestiya Vysshikh Uchebnykh Zavedenii, Khimiya i Khimicheskaya Tekhnologiya. 2009. Vol.52. Iss.6. P.89-91. (russian)

[11] Functional polymethylsiloxane. Patent of Russia Ru 2293746, from 29.12.2005. Muzafarov A.M., Tebeneva N.A. Rebrov E.A., Vasilenko N.G., Buzin M.I., Nikolaeva N.V. (russian)

[12] Functional metallosiloxanes, products of their partial hydrolysis and use. Patent of Russia Ru 2649392, from 11.04.2014. Muzafarov A.M., Tebeneva N.A. Meshkov I.B., Tarasenkov A.N. (russian)

[13] Silicone resin containing metallasiloxanes. Patent $R u$ 2014118468, from 14.11.2012. Rera Vincent (BE), Pierre David (BE). (russian) 